\title{
Supporting Communities of Practice by Enterprise Social Platforms: The Case of an Engineering Company
}

Kirchner, Kathrin; Jørgensen, Rasmus; Bolisani, Ettore; Scarso, Enrico

Published in:

Proceedings of 20th European Conference on Knowledge Management

Publication date:

2019

Document Version

Peer reviewed version

Link back to DTU Orbit

Citation (APA):

Kirchner, K., Jørgensen, R., Bolisani, E., \& Scarso, E. (2019). Supporting Communities of Practice by Enterprise Social Platforms: The Case of an Engineering Company. In Proceedings of 20th European Conference on Knowledge Management (pp. 638-647). Academic Conferences and Publishing International.

\section{General rights}

Copyright and moral rights for the publications made accessible in the public portal are retained by the authors and/or other copyright owners and it is a condition of accessing publications that users recognise and abide by the legal requirements associated with these rights.

- Users may download and print one copy of any publication from the public portal for the purpose of private study or research.

- You may not further distribute the material or use it for any profit-making activity or commercial gain

- You may freely distribute the URL identifying the publication in the public portal 
Supporting Communities of Practice by Enterprise Social Platforms: The Case of an Engineering Company

Kathrin Kirchner ${ }^{1}$, Rasmus Jørgensen ${ }^{1}$, Ettore Bolisani ${ }^{2}$, Enrico Scarso ${ }^{2}$

${ }^{1}$ Department of Management, Technical University of Denmark, Lyngby, Denmark

${ }^{2}$ Department of Management and Engineering, University of Padova, Vicenza, Italy

and International Association for Knowledge Management (IAKM)

kakir@dtu.dk

rajor@dtu.dek

ettore.bolisani@unipd.it

enrico.scarso@unipd.it

Abstract: Information and communication technology (ICT) is a key pillars of supporting CoPs. Virtual CoPs (i.e.: CoPs applying technology enabling asynchronous and distant communications), are growing in numbers. The increase is supported by the availability of new ICT, like for example Enterprise Social Platforms (ESP). ESPS support CoP however empirical based studies investigating ESP application in the context of intentionally developed CoPs are still scarce. This study contributes to filling this gap by exploring CoP participants' behaviour which includes use of an ESP. In particular, we investigate the case of a global engineering company specialized in pharmacy, that has an explicit strategy of developing global CoPs to improve internal knowledge exchange and collaboration processes. At present, 20 active communities involve about 1400 employees. The ESP 'Connect' supports the CoPs. The case company is explored through an online survey comprising 22 questions that was distributed via 'Connect' between September and October 2018. 262 responses were collected (Response rate app. 19\%) from employees located in 8 different countries.

According to the CoP participants can be divided into two groups that have distinctly different behaviour; active and passive. The 'Active' group rely significantly more on external sources and especially on Connect than passive users. Also, the 'active' group is more satisfied with 'Connect' and participate in collaborations. The 'passive' group relies on information from nearest colleagues and rarely contribute to conversations on 'Connect'.

The paper contributes with knowledge about how participants in CoPs supported by ESPs behave differently and thus might be motivated differently.

Keywords: Communities of Practice, Enterprise Social Platform, Knowledge Sharing, Survey

\section{Introduction}

This paper aims to investigate the case of an engineering company specialized in pharmacy, that follows a strategy of developing global CoPs to improve internal knowledge exchange and collaboration processes. Eight years ago, several global CoPs were established to support such strategy: at present, 20 active communities have been developed that involve about 1,400 employees (approximately $90 \%$ of the workforce). The activity of such CoPs is supported by the Enterprise Social Platform (ESP) 'Connect'.

Since the very beginning, studies about Social Media have underlined how participation in these platforms is rather diversified. Already in 2006, Nielsen (Nielsen, 2006) suggested a 90-9-1 rule, which refers to the unbalanced nature of participation in Social Media: 90 percent of users only read content or observe others, while $9 \%$ contribute from time to time and $1 \%$ are heavy contributors. The same occurs in CoPs, where the members play different roles and consequently contribute in different ways, and with different weight, to the life of the community. As indicated by Wenger et al. (2002) the roles assumed by CoPs' members can vary from core to peripheral. Scholars agree that for both CoP and social media their effective functioning depends on having a sufficient and constant number of active users/members (Mäntymäki and Riemer, 2016; Wenger et al., 2002)

In light of the above, the paper explores and characterizes different groups of employees with specific reference to how they interact and participate in intentionally developed CoPs in the organization by means of the introduced Enterprise Social Platform.

\section{Literature Review}

CoP is defined as a 'group of people who share a concern, a set of problems, or a passion about a topic, and who deepen their knowledge and expertise in this area by interacting on an ongoing basis' (Wenger, Snyder, \& McDermott, 2002). The CoP term was coined in a study underlining the importance of learning in the physical and social context of the actual work (Lave \& Wenger, 1991). While some scholars have a perspective on CoP as being self-organised and autonomous (Gabbay \& le May, 2004; Orr, 1996; Urzelai \& Puig, 2018), others propose that CoPs can be intentionally developed to improve organisational knowledge sharing and 
collaboration (Aljuwaiber, 2016; Barbour, Armstrong, Condron, \& Palermo, 2018; Cornes et al., 2014; Jørgensen, Scarso, Edwards, \& Ipsen, 2018; Wenger et al., 2002). In the last years the latter point of view is becoming prevalent especially because a growing number of companies are establishing CoPs as a building block of their knowledge management strategy (Aljuwaiber, 2016; Bolisani and Scarso, 2014).

\subsection{Developing Virtual Communities of Practice}

As widely underlined in the literature, ICT is one of the key pillars of a CoP (Wenger et al., 2009), and particularly of an intentionally created one (Pohjola and Puusa, 2016), since it can streamline internal knowledge sharing processes (Hislop, Bosua, \& Helms, 2018).

Among the various properties of ICT that can support a CoP (i.e. connectivity, multiplicity, codifiability, programmability, and computability; (Nithithanatchinnapat, Taylor, Joshi, \& Weiss, 2016), this study is primarily focused on connectivity. Connectivity provides participants the ability to connect with their community digitally, which is particularly important if members cannot communicate face-to-face (Frank, Sander, Gastaldi, Madini, \& Corso, 2017). This occurs when employees work round-the-clock shifts in operations or when geographical distances or time differences hinder a direct communication (Cordery et al., 2015; Scarso, Bolisani, \& Salvador, 2009). A computer-mediated connection between participants facilitate the development of a relationship that is conducive for knowledge sharing (Lesser \& Storck, 2001), however replacing face-to-face meetings with virtual communication reduces tacit knowledge sharing, CoP performance and outcome (Aljuwaiber, 2016; Schenkel \& Teigland, 2008). Connectivity is essential for the establishment of virtual CoPs (i.e. CoPs that make use of web-based technologies to enable distant and asynchronous communications among members) and explain why they are diffusing very rapidly (Frank et al., 2017). This especially concerns Enterprise Social platforms (ESPS) (Leonardi et al., 2013) that are considered to serve as the "missing link" to connect CoPs to business strategy (Annabi and McGann, 2013).

Actually, ESPs seem to marry perfectly with CoPs, since their operating logic bases on the creation of groups, within which communication, collaboration and information exchange processes are enabled, which are the distinctive characteristics of a CoP. Also, as affirmed by Nithithanatchinnapat et al. (2016), the pervasiveness of Web-enabled social software can potentially transform the nature and use of CoPs, which opens up new and interesting research opportunities to examine the interplay of the new form of ICT and CoPs.

\subsection{CoP participant characteristics}

Age and maturity are two structural CoP characteristics that will change even if no management initiatives takes place, however it is not certain that maturity will change in accordance with age (Dubé, Bourhis, \& Jacob, 2006). One defining element of the CoP-age is the behaviour characteristics of the CoP participants (Dubé et al., 2006; Gongla \& Rizzuto, 2001).

CoP development is described using linear stage models spanning from the initial development to the period in time where CoP activity has come to an end. Research has proposed several CoP development stages that more or less integrate CoP characteristics, CoP processes, critical success factors, and development initiatives (Agrifoglio, 2015; Dubé et al., 2006; Lee, Suh, \& Hong, 2010).

A five stage model was introduced by Gongla and Rizzuto (2001) comprising: Potential, building, engaged, active and adaptive. In the potential stage a nucleus forms which is made up of individuals with a shared interest, but the individuals have yet to fully discover the commonality. Connection is the primary activity as the individual locate one another, communicate, and form relationships. In the building stage, a community starts to take form and define itself in terms of "what the community is going to be and how it is going to build and declare its existence" (Gongla \& Rizzuto, 2001, p. 847), and also develop supportive processes and structure. The community members build a common "understanding of what the community is and what it is not, why it is forming, and how it will function". (Gongla \& Rizzuto, 2001, p. 847). In the engaged stage the community functions with a common purpose. The community grows in size and complexity and the structure and processes comes into action. Access between community members and access to the group knowledge are key functions. "The community really begins building its capability to leverage its explicit and tacit knowledge" (Gongla \& Rizzuto, 2001, p. 847). In the active stage, a community reflects, analyses, and begins to comprehend, define, and assess the value for the members and the organization and "the community further extends its membership and builds relationships to other communities". In this stage the biggest challenge is to sustain momentum. The community draws on their collective knowledge and collaboratively brings benefit to the organization. Members define and share the value that they bring to the larger organization. "Collaboration promotes an understanding throughout the larger organization of the need for and distinct benefit from the community's knowledge and work" (Gongla \& Rizzuto, 2001, p. 847). In the adaptive stage the community adjust continuously to create knowledge and to establish the new structures and processes it 
needs for leveraging its knowledge. The community innovates and generates, creating "new solutions, new offerings, new methods, new processes, and new groups. The community identifies, influences, and even creates trends in its area of expertise" (Gongla \& Rizzuto, 2001, p. 847).

The CoP development stages are characterized by specific behaviour of the core participants. In the engaged stage the core participants 'develop trust in and loyalty to the community, Commit to the community, Outreach to new members, Model knowledge-sharing behaviour, Tell community stories, Actively search for and contribute material to build the community knowledge base, and Promote and participate in knowledge sharing" (Gongla \& Rizzuto, 2001, p. 852). In the active stage "Individuals engage other community members to solve problems and do "real work", The community creates focused work groups, The community connects to and interacts with other communities, The organization actively supports and measures community work, and The organization begins to rely on the community's knowledge to contribute to business value (Gongla \& Rizzuto, 2001, p. 853).

In all the CoP development stages, having an adequate group of active members is crucial to the survival and effective functioning of the community (Wenger et al., 2002). The behaviour characteristics of core CoP participants define the most active participants. But, CoP participation ranges from core to peripheral, the latter being relative inactive compared to the active core participants, and participation on all levels impact the CoP outcome (Wenger et al., 2002). Since inactive participants have rarely been studied despite contributing to the CoP, knowledge about their behaviour characteristics and CoP impact is limited. This study explores active and passive CoP participants in the case where participants interact with each other through the technological platform which supports the community.

\section{Research Method}

On the basis of what emerged from the analysis of the literature, our research aimed to investigate how members of CoPs make use of an ESP to participate in the communities. In particular, the following research question was formulated:

RQ: Which characteristics do distinguish active from passive users of ESP-enabled CoPs?

To answer the above question, the employees of a company were asked that have adopted an ESP to support their CoPs (that the company calls Col, i.e. Community of Interest). Data was collected via a questionnaire that was distributed via the ESP Connect between September and October 2018. The questionnaire included 22 questions aimed to understand how ESP-enabled Cols are supporting knowledge management processes of the company. Together with demographic questions (office country, position, seniority within the company), we asked in how many Cols the employees are member in, what the name of their primary Col is, how long they are already member there and which role they have (Chairman, Key member, Member). We also wanted to know how important different knowledge sources are for their work, for which purposes the Col-software Connect is used and how Cols are evaluated.

The responses were received from employees located in 8 countries (Denmark, France, Belgium, Germany, Switzerland, India, Japan, and United States). After cleaning the data, we got 260 valid answers of employees that perceived themselves as either active or passive users of the Cols facilitated by Connect. For reasons of space, in the findings section only a limited share of the most interesting results is illustrated and discussed.

\subsection{Case context}

The case company (indicated as PHC for reasons of anonymity) is a global engineering company with 15 offices dispersed in Europe, China, India, and USA, that specializes in the pharmaceutical industry, with around 2000 employees of which app. 1400 employees are potential Col members. Employees are expected to consult written engineering guidelines when developing solutions to customers, provide feedback or suggest improvements to the guideline owner, and participate in knowledge development discussions. Employees are also expected to leverage the globally dispersed PHC workforce to resolve problems and find solutions by posting questions online or directly to PHC experts. The company has organized 20 global Cols as central part of its strategy to become a world leading pharma engineering company that has a local presence and use the knowledge of experts around the world.

The Col participants are voluntary practitioners that interact continuously. The Cols define their own task, are responsible for stewarding knowledge within PHC, and have a long-term focus. Consequently they have the characteristics of CoP and this study defines them as such (McDermott \& Archibald, 2010; Wenger et al., 2002). The first Cols were established in 2008 and their activity and impact has been growing steadily since 
then: 2017 saw a 25\% increase in questions asked online (2017: 1053 questions) and 146 project learnings were implemented. Figure 1 shows the time trend of the activity on Connect (2018 data only represents January until August, i.e. not a complete year) The activity is a summary of posts, questions asked, and improvement suggestions from engineering projects (lessons learned). The (red) dots indicate comments.

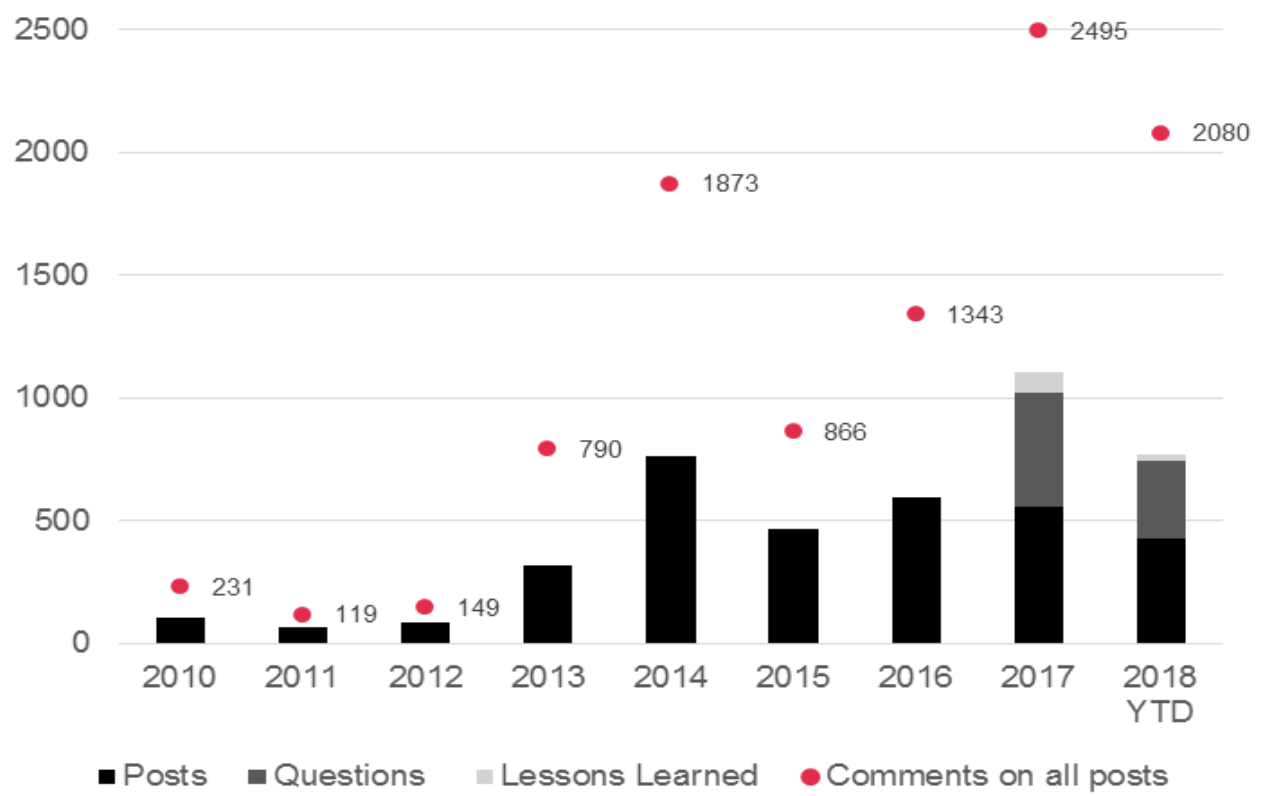

Figure 1: Activity on the Social Enterprise Platform Connect

Each of the 20 Cols represents a competence that has been identified by at least four countries as being a core competence. The Cols are responsible for writing the global engineering standards, and implementing best engineering practice derived from projects throughout the world. They also maintain PHC's knowledge base and obtain answers to problems. Cols are supported by several ICT tool including an Enterprise Social Platform Connect, a global Quality Management System (QMS) and other ICT tools like e-mail, telephone etc. Figure 2 illustrates a Connect feed that is similar to the feed from other social media platforms like Linkedln and Facebook (except for cat videos) Each Col has a Chairman that is overall responsible for the community and Key members engagement, furthermore the Chairman is responsible for the mainly administrative tasks of inviting to meetings, report on Col performance, maintain the dialogue with the Col board, and follow up on budget. A Col has several 'Key members' that are voluntarily appointed to the position because they are recognized experts within their field, and these are central to developing knowledge, sharing knowledge and answering questions. Additionally, any employee can become a 'Col member' and participate in discussions. The Col size ranges from 67 to 373 members

Cols are governed by a board made up by management representatives from the countries and the board is responsible for the budget and strategy. The 'Global Best Practice' department GBP support the Cols in different ways by e.g. facilitating workshops and knowledge sharing, recruiting chairmen and key members to the community, and implementing ICT. 


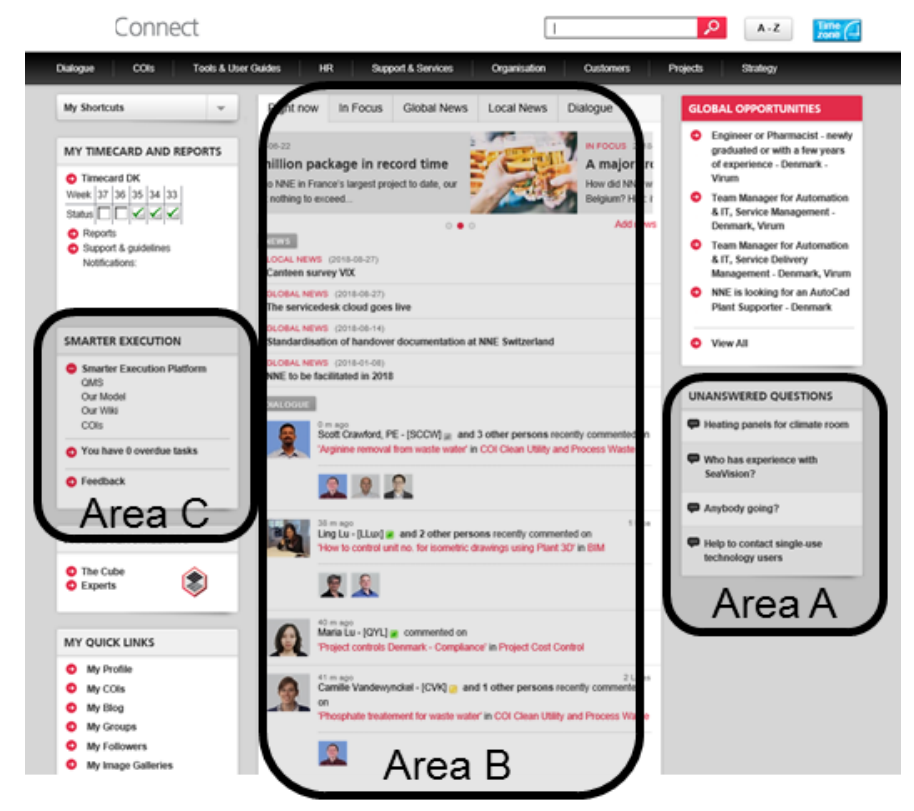

Figure 2: A picture of a Connect feed that share similarities with other social media feeds like Linkedin. Area A is dedicated to questions posed to Cols but are unanswered. Area B is the personal feed with discussions, updates, and questions from the Cols that you are a member of. Area $C$ contain links to feedback on content that you are responsible for and links to engineering standards, the QMS and guidelines.

\section{Findings}

We collected 260 valid answers on a total of 1397 project execution employees who were members of one or more Cols, which means $19 \%$ of the universe. The top three country offices that responded were Denmark (47.3\%), India (13.5\%) and Switzerland (12.7\%). The respondents were typically a member of more than one COI, $7.2 \%$ were members of only one Col, $14.3 \%$ were members of two, and $18.2 \%$ were members of three COls. Some employees reported being a member of more than 10 Cols.

\subsection{Demographics of active and passive users}

According to the answers given, 78 participants perceived themselves as passive users (30\%) that primarily consumed content without contributing by e.g. answering questions. The remaining 182 respondents are characterized as active users (70\%) that reported answering questions from colleagues, motivating others to participate or facilitating mutual exchange of knowledge.

This result is not in line with the large majority of the literature that underlines how a small minority does most of the work in social networks and online communities (Oettl et al., 2018). However other authors, as e.g. Bulgurcu et al. (2018), have examined cases where majority of users were contributors rather than consumer of content. Even if this is an issue that deserves further analysis, the hypothesis can be advanced that an ESP that is adopted to support pre-existing communities having specific job-related interests induces users to participate actively more than a platform whose groups are created after its introduction.

Table 1: Demographics of active and passive users

\begin{tabular}{|l|c|c|c|}
\hline Demographic variable & $\begin{array}{c}\text { General in } \\
\%\end{array}$ & $\begin{array}{c}\text { From them: } \\
\text { Active Users }\end{array}$ & $\begin{array}{c}\text { From them: } \\
\text { Passive Users }\end{array}$ \\
\hline Position & & & \\
$\quad$ Manager & $6.9 \%$ & $77.8 \%$ & $22.2 \%$ \\
Project / Engineering Manager & $19.7 \%$ & $54.9 \%$ & $45.1 \%$ \\
Engineer / Specialist & $73.4 \%$ & $73.2 \%$ & $26.8 \%$ \\
\hline Seniority in the company & & & \\
0-2 years & $22.5 \%$ & $56.9 \%$ & $43.1 \%$ \\
2-5 years & $29.1 \%$ & $69.3 \%$ & $30.7 \%$ \\
5-10 years & $23.3 \%$ & $76.7 \%$ & $23.3 \%$ \\
10-15 years & $11.6 \%$ & $73.3 \%$ & $26.7 \%$ \\
\hline
\end{tabular}




\begin{tabular}{|l|c|c|c|}
\hline More than 15 years & $13.6 \%$ & $77.1 \%$ & $22.9 \%$ \\
\hline Length of membership in primary Col & & & \\
0-6 months & $10.0 \%$ & $38.5 \%$ & $61.5 \%$ \\
6 month - 1 year & $7.7 \%$ & $85.0 \%$ & $15.0 \%$ \\
1-2 years & $13.5 \%$ & $68.6 \%$ & $31.4 \%$ \\
2-4 years & $32.0 \%$ & $66.3 \%$ & $33.7 \%$ \\
More than 4 years & $36.7 \%$ & $78.9 \%$ & $21.1 \%$ \\
\hline Role in primary Col & & & \\
Chairman & $7.7 \%$ & $100 \%$ & $0.0 \%$ \\
Key Member & $20.5 \%$ & $94.3 \%$ & $5.7 \%$ \\
Member & $71.8 \%$ & $59.7 \%$ & $40.3 \%$ \\
\hline
\end{tabular}

Regarding demographics of the participants, and looking at their position in the company, $77.8 \%$ of managers consider themselves as active users, as well as nearly two thirds of engineers and specialists. Interestingly, only $54.9 \%$ of project and engineering managers perceive themselves as active (Table 1). Recently employed employees are more passive than employees with longer seniority, given that new employees more often look for help than contribute with new knowledge. At the beginning of their Col membership employees are rather passive, but then become more active and enthusiastic to contribute, but such enthusiasm seems to get lower over the time. Chairmen and Key members in the Cols are nearly all active users, they really act according to their given role.

\subsection{Characteristics of active and passive users}

Active and passive users rely on different knowledge sources in the company. Table 2 reports their evaluations on a Likert scale from 1 (not important) to 5 (very important) and the results of an independent samples T-Test applied to find significant differences between the two groups of users. Active users rely significantly more on external sources (e.g. conferences, magazines) and especially on Connect than passive users. The other knowledge sources are equally important for both groups of users. In general passive users tend to give less value to any knowledge source in comparison to active users.

Table 2: Relevance of different knowledge sources for active and passive users

\begin{tabular}{|l|c|c|c|c|}
\hline \multicolumn{1}{|c|}{ Knowledge source } & $\begin{array}{c}\text { Active Users } \\
\text { (mean) }\end{array}$ & $\begin{array}{c}\text { Passive Users } \\
\text { (mean) }\end{array}$ & T & Sign. \\
\hline $\begin{array}{l}\text { External source (e.g., } \\
\text { conferences, magazines) }\end{array}$ & 3.25 & 2.72 & -3.385 & .001 \\
\hline Email & 3.69 & 3.73 & .259 & .796 \\
\hline Connect & 3.40 & 2.92 & -3.520 & .001 \\
\hline OurWiki & 3.60 & 3.31 & -1.645 & .103 \\
\hline Phone calls & 3.46 & 3.36 & -.503 & .597 \\
\hline Information Talks and Meetings & 3.95 & 3.95 & -.104 & .989 \\
\hline Formal Meetings & 3.77 & 3.64 & -1.012 & .313 \\
\hline Written documents & 3.96 & 3.82 & -1.110 & .269 \\
\hline
\end{tabular}

The next figures show the percentage distribution of responses given by the two groups, where $100 \%$ corresponds to the total of valid responses of each group (between parentheses in each caption it is indicated the maximum number of possible answers). Both passive and active users are mainly engaged in 'reusing and adapting information inside the company' and 'search and share in their own department' than producing new information or searching externally (see Figure 3). Passive users declare to use stored information more than active users, which, instead, are more involved in the collective production of information and in sharing it also outside their departments.

Figure 4 illustrates how the users interact with their primary COI. Both passive and active users primarily browse content and use OurWiki articles thus both groups make use of the explicit knowledge sources available. There are activities where the two groups are distinguishable as active users are more prone than passive to interact with the Col by contributing to conversations, asking for help, and uploading documents and commenting articles. Some of the passive users reported performing activities typical for 'active users' such as uploading documents and commenting on articles. 


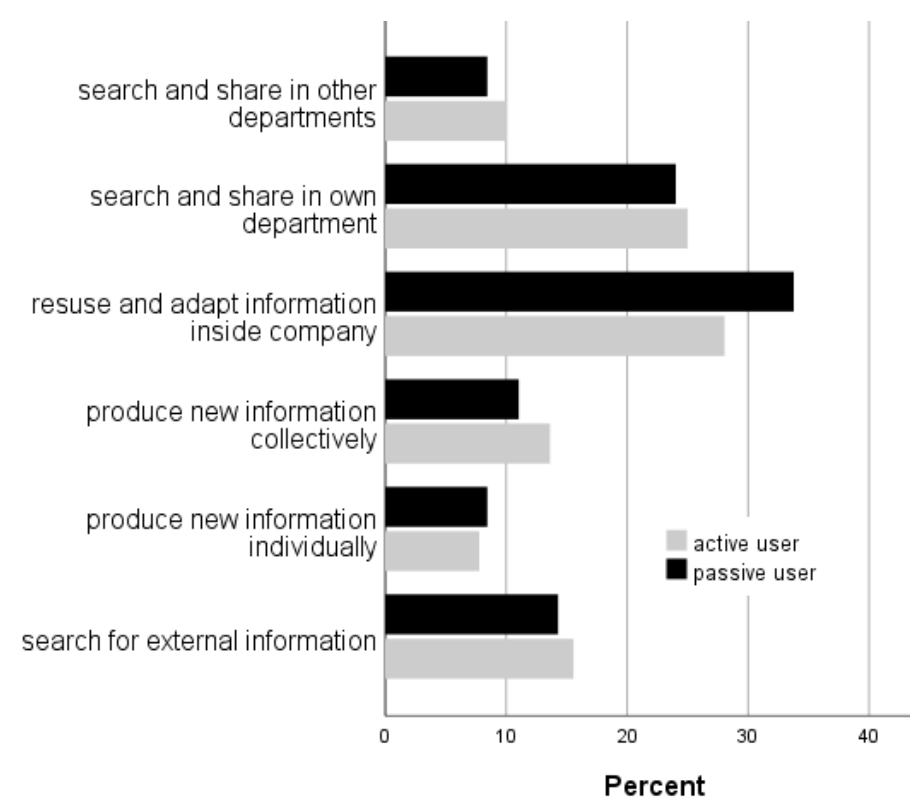

Figure 3: Different ways of participating in knowledge sharing and using information (max 2 answers)

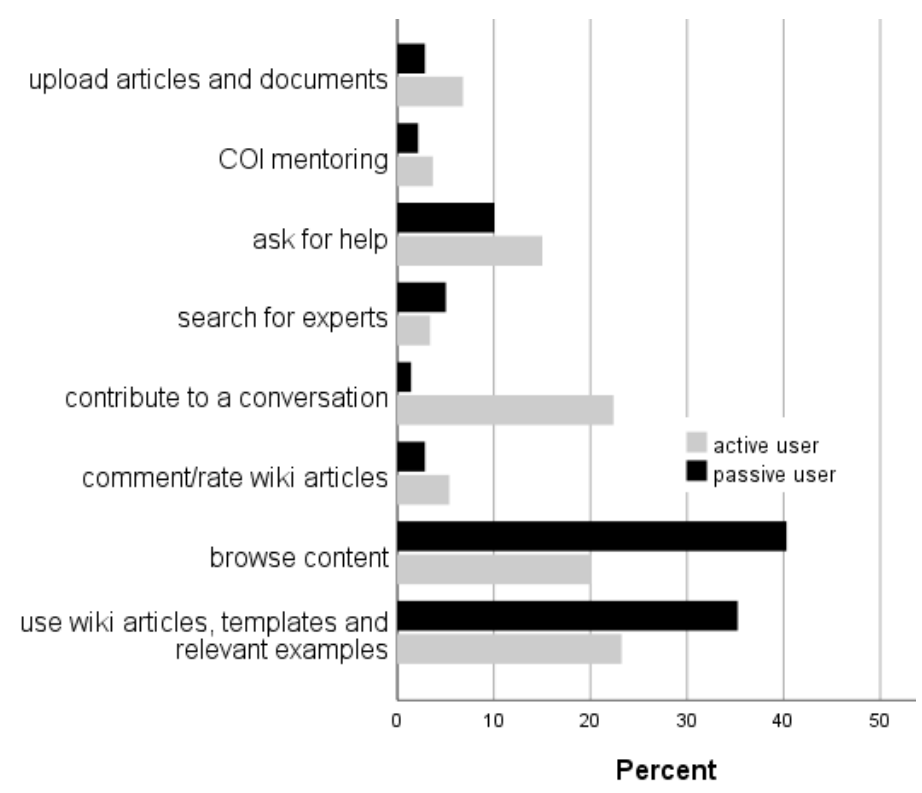

Figure 4: Interaction with primary Col (max 2 answers)

\subsection{Satisfaction with Cols}

Active and passive users were asked to evaluate their primary Col on a Likert scale from 1 (not at all/never) to 5 (to a great deal / always). The Col participants are in the mean only satisfied on a medium level (See Table 3). However, the evaluation is rather different between the two groups. Active users are generally more satisfied with their primary Col than passive users. We applied an independent samples T-Test to find significant differences between the two groups of users. Passive users are significantly less satisfied with the fulfilment of their needs, the improvement of the collaboration, the availability of answers to their questions and the feedback from Col members toward their own ideas. Conversely, the groups agree that the Col offer relevant written guidelines ('OurWiki articles') and this answer is well aligned with how the user groups interact with their primary Col. 
Table 3: Evaluation of primary Col

\begin{tabular}{|l|c|c|c|c|}
\hline The primary COI... & $\begin{array}{c}\text { Active User } \\
\text { (mean) }\end{array}$ & $\begin{array}{c}\text { Passive User } \\
\text { (mean) }\end{array}$ & T & Sign. \\
\hline Fulfils own needs & 3.41 & 2.86 & 5.033 & .000 \\
\hline Improves collaboration & 3.27 & 2.92 & 2.908 & .004 \\
\hline Offers relevant OurWiki articles & 3.55 & 3.42 & .886 & .376 \\
\hline Provides answers to questions & 3.26 & 2.68 & 4.142 & .000 \\
\hline Provides feedback to own ideas & 3.47 & 3.08 & 3.109 & .002 \\
\hline Keeps up with industry & 3.47 & 3.24 & 1.899 & .059 \\
\hline
\end{tabular}

Furthermore, participants were asked to elaborate about their challenges with the Cols in more detail. Both user group reports that they lack time to contribute and that the lack a search functionality to find a certain piece of information quickly (Table 4). It is worth underlining the first comment from passive users that indicates how such user prefer direct contact methods since he/she believe they are more rapid.

Table 4: Challenges with the COIs

\section{Comments from active users}

- "To many noisy comments with no purpose like 'very interesting article' ... The current reward structure does not necessary support the quality in the dialog, but does support quantity"

- [missing] "time from key members to structure and present information"

- $\quad$ "Very few people contribute and there is a feeling that only very complex problems can be shared in Col... so most middle and initial level expertise people hesitate to openly ask questions."

\section{Comments from passive users}

- "If I need help/ input I contact the persons directly... Having to take time to formulate and submit a question on the Col and then wait for an answer that might never come is just not an option in the fast track reality we live in."

- [missing] "interest and motivation to do something together."

- [missing] "focus and encouragement from the management to engage people and use it more (pro)actively"

\section{Discussion}

\subsection{Definition of users}

The study divided CoP participants in two groups; active and passive based on the respondents own reporting; respondents could choose "I'm passive" or choose between different activity they participated in, in which case they were categorized as active. Thus the definition of passive was based on the personal opinion of the respondent. As mentioned earlier some that chose the "passive" option later gave responses that resembled respondents for the "active" category. This could be because participation cannot be simplified into two categories, as CoP participation does not increase in jumps but instead is gradually increased which is supported by the idea of legitimate peripheral participation (Wenger, 1998). There is however the issue about "passive" being a choice based on subjective understanding on what passive CoP participation entails, and future studies could instead build the CoP participant category through responses about specific behaviour to further clarify the behaviour.

If we have at least two different user groups then intentional CoP development in organizations should consider that different groups have different behaviour characteristics. Perhaps the active groups are the primary target group for a CoP development project as these are key to getting the CoP going e.g. from Potential to Building (Gongla \& Rizzuto, 2001). However for the CoP to have a wider organizational impact, CoP development initiatives cannot only consider the active group but must reach the passive group, as the passive participation can result in active participation the future. Furthermore, the passive participation results in the re-use of knowledge when solving work tasks which is beneficial for the company.

The significant difference in CoP satisfaction is also where the two groups clearly distinct. It is however not clear if a respondent is passive because of low satisfaction or if passive behaviour means a lack of knowledge about the Col hence little awareness about the opportunities the CoP offers. Passive users are significantly less satisfied with the feedback and the questions to answers, and one possible reason could be that they belong to specific CoPs that respond slowly. Based on the open answers (Table 4) both groups agree that 'lack of time' is a boundary for CoP participation. It is however not clear why low satisfaction and passive user correlates. 
Future studies could explore if there are different enablers for CoP participation depending on the level of satisfaction.

\subsection{Discussion of active user behaviour}

PHC has chosen to organize their Cols with Chairmen, Key members and Members. Chairman and Key members are the core of the Community whereas anyone can become a member simply by clicking a button on the CoP page on Connect. All the Chairmen (100\%) are categorized as active and $95 \%$ of the key members are active thus organization of the communities appears to support their activity and create business value. Key members are very active on Connect by participating to conversations online and also asking for help.

\subsection{Discussion of passive user behaviour}

A passive user is one that prefers searching for information instead of contributing which could be expected due to the limited experience with the company. The passive users appear reluctant to ask for help at the Col and the difference between active and passive is significant on this point, which could be due to a fear of being perceived as in-competent. Instead a passive user prefers to ask for information inside his/her department which is probably because the nearest colleagues are where the relationships form first.

\section{Conclusions}

As underlined by the literature, members of a CoP can be divided into distinct groups according their level of participation. This study dealt with such topic by categorizing and exploring CoP participation in a global engineering firm where intentionally developed CoPs are supported by an ESP. Research data was collected by distributing a questionnaire through the platform yielding 260 responses that were used for the analysis.

Two groups were identified; active and passive. The active group appear to be central for both knowledge development and sharing and also for collaboration. The central members of the Col's are Key members and Chairman and they behave, as expected, as active users. Employees with a short seniority typically result to be inactive members. This is not surprising as new employees could be expected to primarily search for knowledge and information instead of contributing.

This study highlights the difference between CoP participants in terms of different behaviour (e.g. inactive search inside their own department and rarely use 'Connect', whereas 'active' participate in collaborations, contribute to conversations, and search for knowledge externally). This knowledge could support managers or $\mathrm{CoP}$ mentors that wish to increase CoP activity by guiding passive employees towards more active behaviour.

The response level was app. 19\% which is acceptable. One limitation of the study is that the questionnaire was distributed through Connect thus employees that rarely use Connect, on holiday or on customers projects would have less chance of seeing it.

The findings of the present study pave the way for further studies. First, future research should make a more detailed analysis by subdividing CoP's members in more than the only two groups of passive and active users, especially to understand if it is possible to identify a typical path that leads a passive user to become a very active one. Second, the correlation between being passive and dissatisfied should be explored in order to understand how CoP activity can be increased. Thirdly, the individual Cols could be studies to understand if the specific Col performance influence the participants engagement.

\section{References:}

Agrifoglio, R. (2015) Knowledge Preservation Through Community of Practice. Cham: Springer International Publishing.

Aljuwaiber, A. (2016) Communities of practice as an initiative for knowledge sharing in business organisations : a literature review. Journal of Knowledge Management, 20(4), 731-758.

Annabi H., McGann S.T. (2013) "Social media as the missing link connecting communities of practices to business strategy", Journal of Organizational Computing and Electronic Commerce, Vol. 23, pp 56-83.

Barbour, L., Armstrong, R., Condron, P. and Palermo, C. (2018) "Communities of practice to improve public health outcomes: a systematic review", Journal of Knowledge Management, Vol.22, No. 2, pp 326-343.

Bolisani E. and Scarso E. (2014) "The place of communities of practice in knowledge management studies: a critical review", Journal of Knowledge Management, Vol. 18, No. 2, pp 366-381

Bulgurcu, B., Van Osch, W. and Kane, G.C. (2018)"The rise of the promoters: user classes and contribution patterns in enterprise social media", Journal of Management Information Systems, Vol. 35, No. 2, pp 
610-646.

Cordery, J.L., Cripps, E., Gibson, C. B., Soo, C., Kirkman, B. L. and Mathieu, J.E. (2015) "The Operational Impact of Organizational Communities of Practice: A Bayesian Approach to Analyzing Organizational Change", Journal of Management, Vol. 41, No. 2, pp 644-664.

Cornes, M., Manthorpe, J., Hennessy, C., Anderson, S., Clark, M. and Scanlon, C. (2014) "Not just a talking shop: practitioner perspectives on how communities of practice work to improve outcomes for people experiencing multiple exclusion homelessness", Journal of Interprofessional Care, Vol. 28, pp 541-546.

Dubé, L., Bourhis, A. and Jacob, R. (2006) "Towards a Typology of Virtual Communities of Practice", Interdisciplinary Journal of Information, Knowledge, and Management, Vol. 1, pp 69-93

Frank, A. G., Sander, N., Gastaldi, L., Madini, E., \& Corso, M. (2017). An assessment model for virtual communities of practice: a study in the oil and gas industry. Knowledge Management Research \& Practice, 15(4), 507-522.

Gabbay, J. and le May, A. (2004) "Evidence based guidelines or collectively constructed "mindlines?" Ethnographic study of knowledge management in primary care", British Medical Journal (Clinical Research Edition), 329(level 2), 1013.

Gongla, P. and Rizzuto, C.R. (2001) "Evolving communities of practice: IBM Global", IBM Systems Journal, Vol. 40, No. 4, pp. 842-862.

Hislop, D., Bosua, R. and Helms, R. (2018). Knowledge Management in Organizations: A Critical Introduction (4th ed.). Oxford University Press.

Jørgensen, R., Scarso, E., Edwards, K. and Ipsen C. (2019) “Communities of practice in healthcare: A framework for managing knowledge sharing in operations", Knowledge and Process Management, forthcoming

Lave, J. and Wenger, E. (1991). Situated Learning : Legitimate Peripheral Participation (1st ed.). Cambridge, UK: Cambridge University Press, Oxford.

Lee, J., Suh, E. and Hong, J. (2010) "A maturity model based CoP evaluation framework: A case study of strategic CoPs in a Korean company", Expert Systems With Applications, Vol. 37, No. 3, pp2670-2681.

Leonardi, P.M., Huysman, M. and Steinfield, C. (2013) "Enterprise social media: Definition, history, and prospects for the study of social technologies in organizations", Journal of Computer-Mediated Communication, Vol. 19, No. 1, pp 1-19.

Lesser, E.L. and Storck, J. (2001) "Communities of practice and organizational performance", IBM Systems Journal, Vol. 40, No. 4, pp 831-841.

Mäntymäki, M. and Riemer, K. (2016), "Enterprise social networking: A Knowledge management perspective", International Journal of Information Management, Vol. 36, pp. 1042-1052.

McDermott, R. and Archibald, D. (2010) "Harnessing Your Staff's Informal Networks", Harvard Business Review, Vol. 88, No. 3, pp 82-89.

Nithithanatchinnapat, B., Taylor, J., Joshi, K.D. and Weiss, M.L. (2016) "Organizational communities of practice: Review, analysis, and role of information and communications technologies", Journal of Organizational Computing and Electronic Commerce, Vol. 26, No. 4, pp 307-322.

Nielsen, J. (2006). Participation inequality: encouraging more users to contribute. Nielsen Norman Group, http://www.useit.com/alertbox/participation_inequality.html (accessed on 13.03.2019).

Oettl, C., Berger, T., Böhm, M., Wiesche, M. and Krcmar, H. (2018) “Archetypes of Enterprise Social Network Users", Proceedings of the 51st Hawaii International Conference on System Sciences, pp 2036-2045.

Orr, J.E. (1996) Talking about machines : An ethnography of a modern job. Cornell University Press, New York.

Pohjola, I. and Puusa, A. (2018) "Group dynamics and the role of ICT in the life cycle analysis of community of practice-based product development: a case study", Journal of Knowledge Management, Vol. 20, No. 3, pp 465-483.

Scarso, E., Bolisani, E. and Salvador, L. (2009) "A systematic framework for analysing the critical success factors of communities of practice", Journal of Knowledge Management, Vol. 13, No. 6, pp 431-447.

Schenkel, A. and Teigland, R. (2008) "Improved organizational performance through communities of practice", Journal of Knowledge Management, Vol. 12, No. 1, pp 106-118.

Urzelai, B. and Puig, F. (2019) "Developing international social capital: The role of communities of practice and clustering", International Business Review, Vol. 28, No. 2, pp 209-221.

Wenger, E. (1998) Communities of practice, Cambridge UniversityPress, Cambridge.

Wenger, E., Snyder, W. M. and McDermott, R. (2002) Cultivating Communities of Practice: A Guide to Managing Knowledge, Harvard Business School Press, Boston, MA.

Wenger, E., White, N. and Smith, J.D. (2009) Digital habitats: Stewarding technology for communities, CPsquare. 